competitor of which Marincola was previously chair: eLife, an elite journal funded with more than $£ 15$ million (US\$24 million) from the Wellcome Trust in London, the Max Planck Society in Munich, Germany, and the Howard Hughes Medical Institute in Chevy Chase, Maryland. "Their appeal is that there is quality inferred from the brand," notes Marincola.

"We are working to evolve all of PLOS towards a world where papers are only rejected when they are scientifically invalid," says Eisen. PLoS ONE already adopts that approach, but the publisher has six moreselective journals, including PLoS Medicine and PLoS Biology. Marincola will not be drawn on whether these might become less selective, although she says that in the longer term, "we would like very much to be able to move away from our current system of peer review altogether". The organization's research arm, PLOS Labs, founded this year, aims to develop and test concepts for peer review after papers have published.

Others have different priorities. "One of the areas I would love to see PLOS push is doing open science cheaper," says Jonathan Eisen, Michael's brother and an evolutionary biologist who is on the editorial board of PLoS Computational Biology. Reducing the $\$ 1,350$ author fee for its lowest-cost journal, PLoS ONE, also makes sense tactically, says Joseph Esposito, a publishing consultant based in New York City, because it will make it harder for new entrants to break into the megajournal market. "Right now, PLOS is by far the scale leader. They should play that card now and play it aggressively," he says. But Marincola says that PLOS has not raised its prices in four years, and waived about $\$ 4.3$ million in publishing fees last year.

Making everything as cheap as possible is not a pressing priority, agrees Damian Pattinson, editorial director of PLoS ONE. Like Marincola, he thinks the immediate focus will be on iterative improvements to the

\section{"The packaging of ajournal will become less and less important."} publishing process. "For years, journals have got away with treating authors like scum," he says. Open access focuses publishers' minds on giving authors services they value, such as faster turnaround, better websites and metrics on who is viewing articles, he adds.

To Michael Eisen, some of the most visible manifestations of innovation are with other publishers - such as F1000 Research in London, which already uses open peer review after papers are published. "They are doing lots of things that PLOS should have done five years ago," he says. "PLOS has created the landscape that has enabled others to flourish, which is great. The question is, how can it continue to be innovative?"

\title{
GREENHOUSE GRID
}

Scientists who monitor the build-up of carbon dioxide in the atmosphere depend on data collected by the Scripps Institution of Oceanography and the US National Oceanic Atmospheric Administration (whose networks overlap in some places). A private firm, Earth Networks, runs a smaller US-based system.

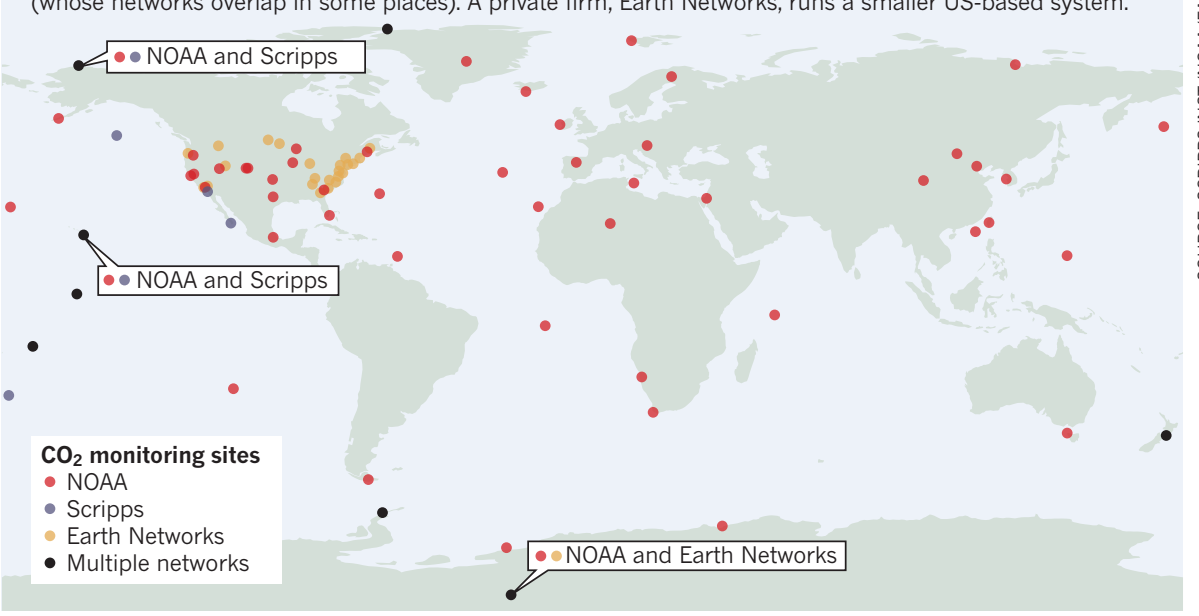

\section{Budget crunch hits Keeling's curves}

\section{Scientist struggles to maintain long-standing carbon dioxide record and more recent atmospheric-oxygen monitor.}

\section{BY JEFF TOLLEFSON}

$\mathrm{L}$ ate last month, officials at California's Scripps Institution of Oceanography turned to Twitter seeking donations to maintain the iconic 'Keeling curve', a 55 -year record of rising atmospheric carbon dioxide levels. An appeal for funds launched in July had attracted only a few small contributions, not nearly enough to keep the programme going.

Scripps geochemist Ralph Keeling, who took over the $\mathrm{CO}_{2}$ measurements started by his father Charles, is neither surprised nor disappointed. "That's more a fishing expedition than anything," he says of the nascent crowdsourcing at Scripps in La Jolla. But he is worried.

For years, he has struggled to cobble together enough cash to support the $\mathrm{CO}_{2}$ programme and an atmospheric-oxygen record that he pioneered in 1989. Bouncing between grant programmes designed to fund shortterm projects, not long-term monitoring, he has cut staff and streamlined operations to keep the records going.

But now, with his funds running dry, he wonders about the future. "Things have never been this dire before," he says.

Much has changed since 1958, when Charles Keeling took his first $\mathrm{CO}_{2}$ measurements atop
Mauna Loa in Hawaii. The programme he started now monitors $\mathrm{CO}_{2}$ at 13 sites, from the South Pole to Alaska (see 'Greenhouse grid'). The National Oceanic and Atmospheric Administration (NOAA) runs a larger network that overlaps with the Scripps system, helping both teams to ensure that their measurements are correct. These data, along with other measurements from researchers around the world, flow into models designed to study how carbon moves through the environment.

The complement to the Keeling curve is Ralph Keeling's atmospheric-oxygen record, which NOAA does not replicate. Keeling has documented a decrease in oxygen levels that is due to fossil-fuel combustion, which uses up oxygen and releases $\mathrm{CO}_{2}$. By accounting for both $\mathrm{CO}_{2}$ and oxygen levels in the atmosphere, scientists have calculated that oceans and plants each absorb roughly one-quarter of humanity's $\mathrm{CO}_{2}$ emissions, leaving half to build up in the atmosphere.

"We expected an answer close to that, more or less, but Ralph Keeling was the first to provide the measurements," says Pieter Tans, who heads NOAA's carbon-cycle and greenhousegas group in Boulder, Colorado.

Keeling says that he received around US $\$ 700,000$ annually for the $\mathrm{CO}_{2}$ programme through paired support from the National 
- Science Foundation (NSF) and the Department of Energy (DOE) until three years ago, when the NSF halted funding. With staff cuts, he has been able to maintain operations with a budget of around $\$ 350,000$. He has also partnered with Earth Networks, an atmospheric-monitoring company based in Germantown, Maryland, which has deployed a sensor for him at Mauna Loa to reduce the costs for Scripps. His latest grant application to the DOE is pending, but in the meantime he is operating on spare funds.

The situation is murkier for the oxygen measurements, which the NSF and NOAA supported for more than two decades. The NSF pulled the plug in 2009, and Keeling's NOAA grant could run out in early January. In an effort to keep things going, Keeling says that he went back to the NSF and was assured that he would get about $\$ 350,000$ from the Division of Polar Programs this autumn. (NSF officials say that they cannot comment on pending grants.) That money would carry him into next year, but it remains unclear what will happen after that. Jim Butler, director of NOAA's Global Monitoring Division in Boulder, says that NOAA cannot simply fold Keeling's $\mathrm{CO}_{2}$ stations into its own observations budget, given that the value of having two $\mathrm{CO}_{2}$ networks is scientific independence. The oxygen measurements, by contrast, would fit nicely into NOAA's portfolio, Butler adds, but his division's budget has shrunk by $12 \%$ since 2011, with further cuts expected this fiscal year. Budget constraints have already forced the agency to reduce staff and shut down monitoring at ten sites.

"NOAA's budget is getting hammered, and it's increasingly difficult to fund things like Ralph's programme," Butler says. "All I can do right now is provide moral support to keep it going year by year until we come up with a plan."

For a while, it seemed that commercial interests might pick up some of the slack. Working with Scripps, Earth Networks announced plans in 2011 to deploy a global network of 100 greenhouse-gas monitoring stations. But two years later, with climate regulations on the back burner in Washington DC, the company is operating just 25 stations. "We really don't have any material customers at this point," says Earth Networks' president Bob Marshall.

Keeling has considered approaching private foundations for help, but acknowledges that atmospheric monitoring is an unusual target for philanthropy. Moreover, he says, a private donor would probably want to see evidence of stable government support before committing. "The difficulty of keeping these things going long term, even within the government, needs to be recognized," he says.

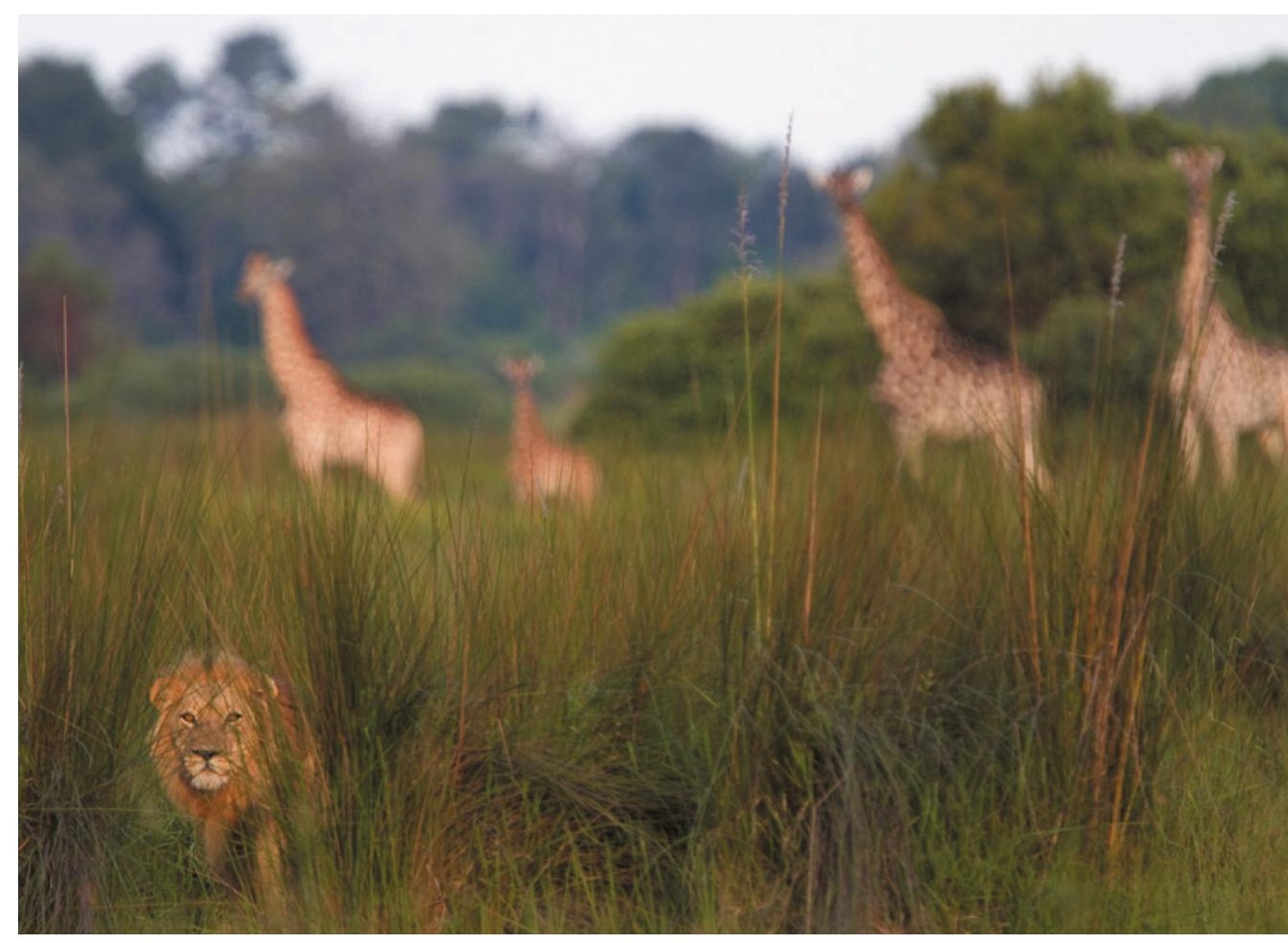

Lion numbers have fallen sharply in recent decades, in large part because of killing by humans.

\section{ECOLOGY}

\section{Fences divide lion conservationists}

\section{Some say enclosures offer protection, others maintain they are a menace.}

\section{BY TRACI WATSON}

$\mathrm{T}$ Times are grim for the king of the beasts. Roughly 35,000 African lions roam the savannahs ${ }^{1}$, down from more than 100,000 half a century ago, thanks to habitat loss, declining numbers of prey animals and killing by humans. One study estimated that fewer than 50 lions (Panthera leo) live in Nigeria and reported no sign of the animal in the Republic of the Congo, Ghana or Côte d'Ivoire $^{2}$.

Now a king-sized controversy is brewing over a proposal to shore up lion populations before it is too late. A prominent lion researcher has called for limiting conflict between humans and lions by erecting fences around reserves containing wild lions. The idea has split scientists, with those opposed to the idea arguing that fences could do more harm than good. The ensuing debate has also laid bare fundamental differences of opinion about how to preserve lions and other species, and raised concerns that a key challenge to lion conservation - lack of funds - is being ignored while scientists trade jabs about fences.

When he began the research that kicked

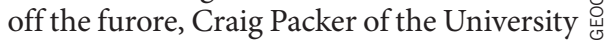
of Minnesota in St Paul, who studies lions at $\frac{\vec{z}}{2}$ Tanzania's Serengeti National Park, intended 을 to determine only the cost of conserving lions. But something more provocative emerged from his data. In work reported earlier this oे year in Ecology Letters $^{3}$, he and 57 co-authors calculated lion densities at 42 African reserves and found, Packer says, that the only variables that matter for density are "dollars and fence - nothing else". He adds that "the fence has a very profound, powerful effect", because it prevents lions from preying on livestock and people, meaning fewer lions are killed in retaliation. Packer would like to see fences around even some of the largest protected areas such as Tanzania's 47,000-square-kilometre Selous Game Reserve.

But the paper triggered heated discussion, 